\title{
The Venus effect in real life and in photographs
}

\author{
Marco Bertamini and Rebecca LaWson \\ University of Liverpool, Liverpool, England \\ LUKE JONES \\ University of Manchester, Manchester, England \\ AND \\ MADELINE WinTers \\ University of Liverpool, Liverpool, England
}

\begin{abstract}
The toilet of Venus is the subject of many paintings. Typically, Venus appears with a small mirror in which her face is visible. Observers tend to say that Venus is admiring herself in a mirror, even when the location of the mirror makes this impossible. We demonstrate that the Venus effect is not specific to paintings by showing that it occurs in real life (Experiment 1) and in photographs (Experiments 1-4). The original description of the effect implied that observers describe Venus as seeing in a mirror what they (the observers) see. We used different photographs to compare the responses when the person in front of the mirror could or could not see him or herself and when the image of his or her face was or was not visible to the observer. Observers tend to state that a person can see his or her own reflection when he or she appears near a mirror, whether or not his or her face is visible in the mirror. A task based on a top-down view of a room confirmed that people lack sensitivity to the role of the viewpoint (Experiment 5). We discuss these findings in relation to other evidence of difficulty in understanding what is visible in a mirror.
\end{abstract}

Titian is usually credited with reintroducing the theme of the toilet of Venus into Renaissance art, a theme that was popular in late Hellenistic and Roman art (PoglayenNeuwall, 1934). From then onward, a small mirror is often part of the composition, either in the hands of Venus or held for her by someone next to her.

Let us take as an example the famous Toilet of Venus by Velázquez (1599-1660). This is also known as the Rokeby Venus, and the image can be seen on the National Gallery Web site (www.nationalgallery.org.uk/; Baker \& Henry, 2001). A woman, Venus, is lying on a bed and her son, Cupid, holds up a mirror for her. Her face is seen centered in the small mirror. Most people describe the scene by saying that she is looking at herself (Bertamini, Latto, \& Spooner, 2003). Note, however, that the viewpoint of the observer is different from the viewpoint of Venus; that is, the observer is not behind Venus with respect to the mirror. Therefore, what can be seen in the mirror differs for the observer and for Venus. A reasonable implication for a small mirror is that if the observer sees Venus's face nicely framed in the mirror, Venus should see the observer's face. Each layout is unique, but in many famous paintings, the scene is not compatible with Venus looking at her own reflection. A striking example is the Venetian Venus at Her Toilette, c. 1582, by Veronese (1528-1588), which can be seen on the Joslyn Museum Web site (www.joslyn.org/). The Lady and the Unicorn (15th century), which can be seen on the Cluny Museum Web site (www.musee-moyenage.fr/), is an example in which an animal, rather than a person, is shown in the mirror. Many more examples exist in movies and television productions where an actor is seen reflected in a mirror but is standing to the side of the mirror.

The fact that observers claim that Venus is seeing herself (when she cannot, given the layout) has been named the Venus effect (Bertamini, Latto, \& Spooner, 2003). Consistent with naive observers' statements, art historians also tend to describe the scene as showing Venus looking at herself (e.g., Poglayen-Neuwall, 1934, p. 363, with reference to Titian's painting in the Hermitage collection).

Bertamini, Latto, \& Spooner (2003), in the original article, made clear that the Venus effect has no direct implications for what Velázquez or any other painter intended to depict. The Venus effect is about how observers describe the scene. The effect does not imply that anything is wrong with the image. For instance, a scene could easily be arranged to match the layout in the Rokeby Venus. What would be the case, however, is that the woman would not see her own face in the mirror. What artists do is to produce an image that tells a certain story, exploiting, consciously or not, how observers tend to interpret images.

M. Bertamini, m.bertamini@liverpool.ac.uk 


\section{The Venus Effect and Other Errors About Mirrors}

The Venus effect is not an isolated case of a difficulty that people have with mirrors. On the contrary, it has been documented that simple questions about mirrors can be challenging for a large part of the population. We can distinguish three types of mistakes. (1) The early error occurs when people predict that they will be able to see themselves in a mirror before they arrive in front of it (Bertamini, Spooner, \& Hecht, 2003; Croucher, Bertamini, \& Hecht, 2002). That is, people overestimate what is visible in a mirror, and this applies to questions about where they could see themselves or where they could see other objects. This is true for a paper-and-pencil task, as well as in a real room with a covered up mirror. (2) People make the mistake of claiming that in the case of their own image, the size of the projection on a mirror surface is the same as the size of their body (Bertamini \& Parks, 2005; Gombrich, 1960; Lawson \& Bertamini, 2006). That is, many people believe that a mirror the size of their own face is necessary to see the whole face. In fact, the projection is half the physical size. (3) People also claim that in the case of their own image, projection size decreases with distance, so that they can see themselves in a small mirror if they move far enough away. In fact, the projection size of the body of the observer does not change with the distance of the observer (Bertamini \& Parks, 2005; Lawson, Bertamini, \& Liu, 2007). ${ }^{1}$

On one hand, the Venus effect is similar to the projection size error in that people make a mistake while looking at a mirror (and therefore have visual information present), as opposed to being asked a hypothetical question about a mirror. On the other hand, the Venus effect is also related to the early error, because for both, the correct answer requires an appreciation of how what is visible in a mirror varies with the viewpoint. In the final discussion, we will return to the relationship between the Venus effect and other findings about mirrors.

Expectations on the part of the observer are also likely to play a part in the Venus effect. The paintings in which Venus is shown with a small mirror are scenes in which a beautiful woman (Venus) is shown using a mirror as a tool during her toilet. It is therefore important to bring the phenomenon into the laboratory to test it under wellcontrolled conditions and using different tasks.

\section{Plan of the New Experiments}

The original article gave the impression that the Venus effect is about how people read the image from a picture and that, in this sense, the Venus effect is specific to picture perception (Bertamini, Latto, \& Spooner, 2003). Here, we argue against this view. In Experiment 1, we collected data using a mannequin in a room with a small mirror to document the existence of the Venus effect in a situation close to everyday life.

In addition, the original description of the Venus effect suggested that observers say that Venus can see herself because the observer sees Venus's face reflected. Perhaps mirrors are treated as pictures, and in a picture, everybody sees the same image. We tested this aspect of the phenomenon in Experiment 2A using photographs in which the individual in the scene can or cannot see himor herself and in which the observer can or cannot see the individual's face. We combined these two variables to give a $2 \times 2$ factorial design. In Experiment 2B, we used two of the photographs but asked an additional question about the perceived position of Venus. In Experiment 3, we extended the results of Experiment 2A, using different images, a larger sample, and a forced choice task instead of a free description.

Experiment 4 was a two-alternative forced choice (2AFC) task about which of two images showed a person looking at him- or herself in a mirror. New images were produced that showed the person's feet, which should make the spatial layout of the scene clearer. In this experiment, we tested whether it is possible, at least under some conditions, to completely eliminate the Venus effect.

Finally, in Experiment 5, we used a top-down diagram of a room to test what portion of the room people believe that an observer can see from a given standpoint. These stimuli were therefore fundamentally different from the photographs used before. With a top-down view, there is no ambiguity about the relative positions of the person and the mirror. In agreement with the Venus effect, people tended to take relatively little account of the location of the viewpoint and gave similar answers whether the observer was located to the left or the right of the mirror.

\section{EXPERIMENT 1}

In a small room, we arranged a stationary female mannequin and a small mirror so that from outside the door, one would see the face of the mannequin in the mirror. We asked naive participants to describe what was in the room and compared their answers with those of another group of naive participants who, instead of seeing the room itself, saw a photograph of the room taken from the same viewpoint. Note that, although the photograph matched what would be visible to a person standing by the window, many differences existed between the free view of a room (where only the direction from which one is looking is constrained) and a printed image. Rich cues to depth, such as disparity and motion parallax, were available in the room but were absent in the photograph, making it harder to extract spatial information about the physical location of the mannequin and the mirror.

We predicted that similar errors would be found in the real-room and photograph conditions. We believe that the Venus effect does not depend on the richness of the stimulus, because the effect does not originate from ambiguity of the layout of the scene but, rather, from a fundamental difficulty in understanding what is visible in a mirror. As was discussed in the introduction, this prediction is based on other errors that people make when asked to predict what is visible in a mirror.

\section{Method}

Participants. The participants were 44 undergraduate students at the University of Liverpool (34 female). Their average age was 20.6 years $(S D=5.3)$. 
Design and Procedure. The participants were assigned to one of two conditions: real room or photograph. A mannequin $(178 \mathrm{~cm}$ tall $)$ and a mirror $(34.5 \times 49.5 \mathrm{~cm}$, including the frame; $30 \times 45 \mathrm{~cm}$ mirror surface) were positioned in a small room $(210 \times 285 \mathrm{~cm})$, as is illustrated in Figures 1 and 2. The observers did not enter the room; instead, they looked into it from a rectangular window that was part of the door. This observation window was $12 \mathrm{~cm}$ wide and $43 \mathrm{~cm}$ high. The mannequin stood $50 \mathrm{~cm}$ from the wall on which the mirror hung and $200 \mathrm{~cm}$ from the observation window.

The participants were asked to look through the observation window. They were asked to describe what was going on in the room and what the mannequin was doing. In the rare case in which these instructions were insufficient to elicit information about what the mannequin was seeing, the additional question of what the mannequin would see in the mirror was asked. The participants were allowed to move their heads and eyes and to scan the whole room, but the window forced them to look from a specific direction. When the participants made relevant observations (e.g., "the mannequin is admiring herself in the mirror"), the experiment terminated. The experimenter noted down all observations and comments made by the participants.

The participants in the second condition were presented with a color photograph (Figure 2, left panel). This photograph was taken from the viewpoint of the participants in the first condition. The task was the same as that in the real-room condition.

\section{Results}

The answers given by the participants were classified on the basis of what they claimed that the mannequin could see. There were three categories: self if the Venus effect occurred (they described the mannequin as looking at herself in the mirror); observer if the Venus effect did not occur (they described the mannequin as looking at the observer or the camera taking the photograph); or other if participants described her as being able to see parts of the room, or just objects in the room, or made observations such as "she is looking to her right, but not at herself."

In the real-room condition, 16 people stated that Venus was looking at herself (self), 4 people stated that she could see the observer (observer), and 2 people stated that she could see something else in the room (other).

Of the observers who saw the photograph, 14 stated that Venus could see her own reflection in the mirror (self), 2 stated that she could see the camera (observer), and 6 stated that she could see other parts of the room or that she could just see something else (other) - for example, "she can see to her right, the other half of the photo."

Figure 3 shows the response frequencies in the different conditions. Because the frequencies in some cells of the design were below 5, we performed a Fisher exact test (Freeman \& Halton, 1951). We found no significant difference in the frequency of each response between the two conditions $(p=.313)$. We performed an additional test in which we grouped the room and photo conditions together. A chi-squared test was conducted to assess

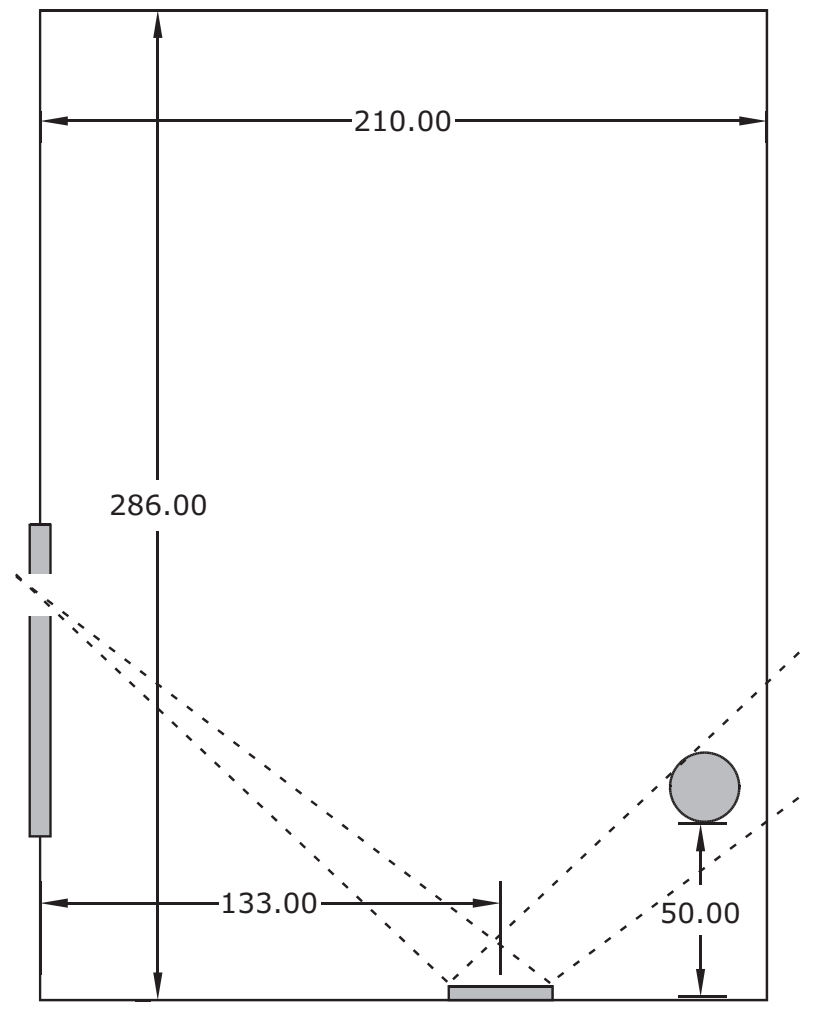

The Scene From the Observer's Viewpoint

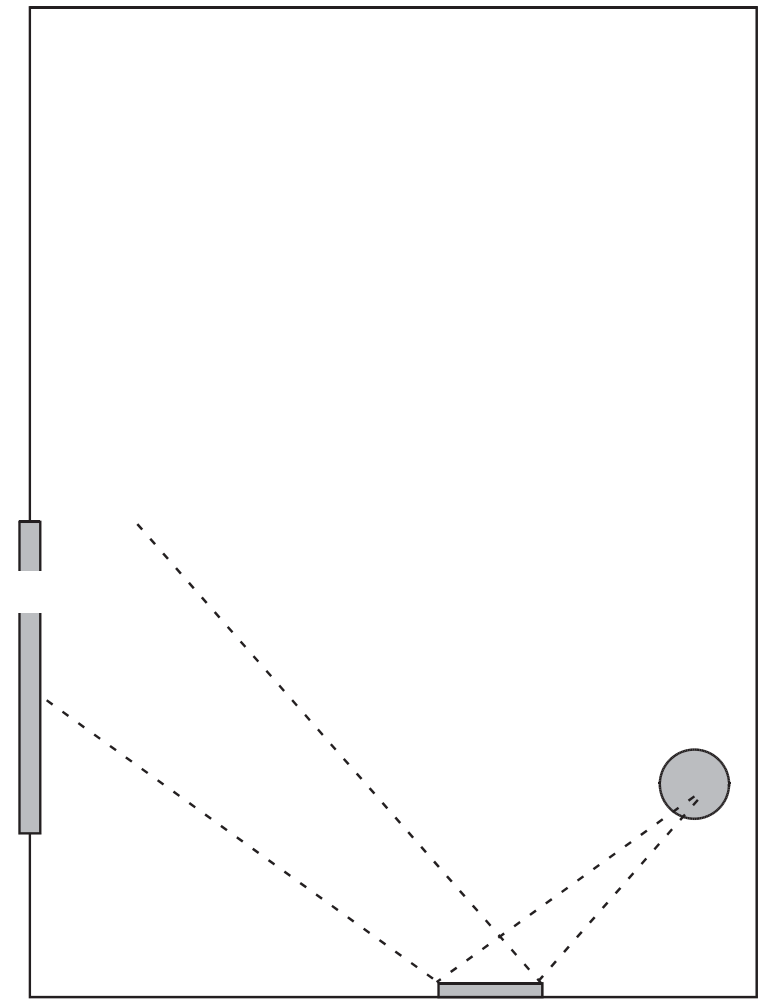

The Scene From the Mannequin's Viewpoint

Figure 1. The gray circle is the position of the mannequin in Experiment 1. From the observation window, the observer could see the mannequin's face in the mirror (dashed lines, left panel). The mannequin could see the observer in the mirror (dashed lines, right panel). 


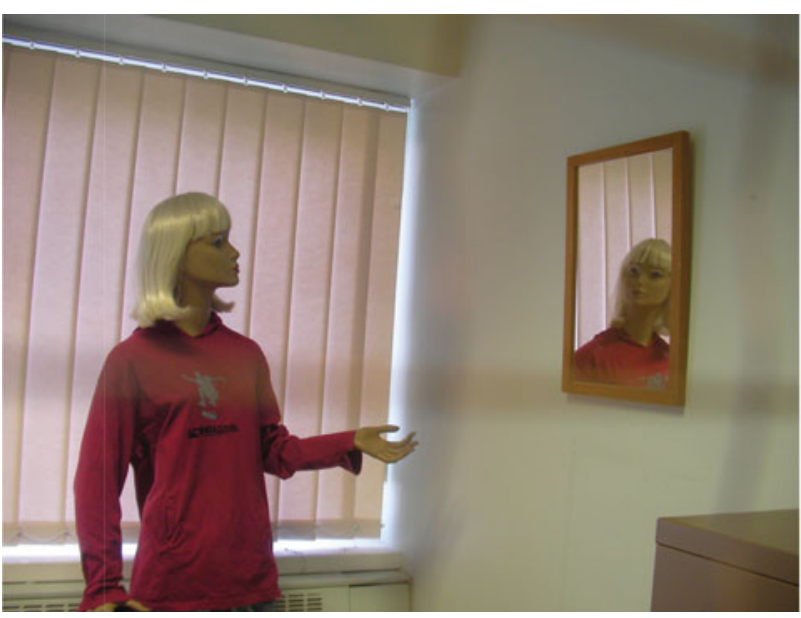

The Scene From the Observer's Viewpoint

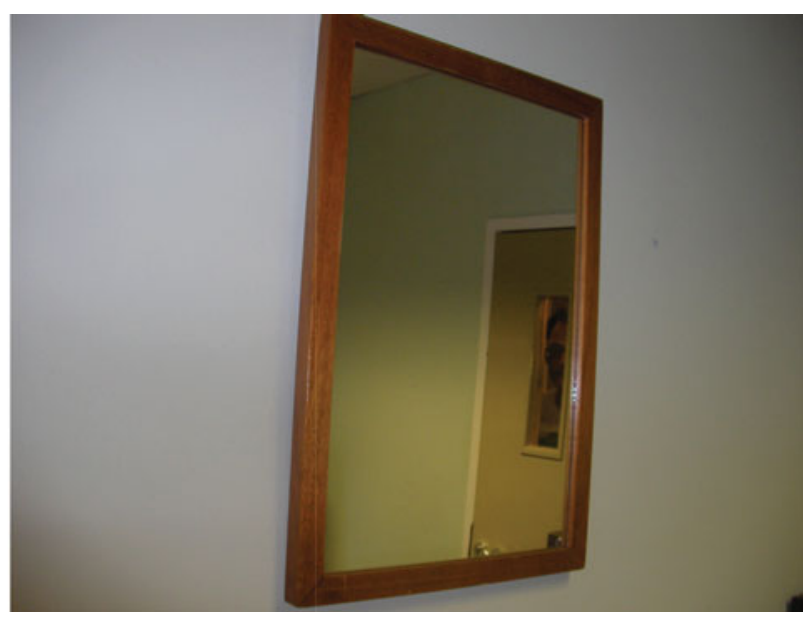

The Scene From the Mannequin's Viewpoint

Figure 2. Photograph used in Experiment 1 (on the left) and a photograph taken near the mannequin's viewpoint (on the right). From the mannequin's viewpoint, it is possible to see the observation window where the observer stood.

whether the three responses were equally frequent. The Venus response was the most common, and the frequencies were significantly different $\left[\chi^{2}(2)=10.86, p=\right.$ .004].

We conclude that the Venus effect can be replicated in a real-life setting and that, remarkably, it is just as strong for a person standing a couple of meters away from Venus as for a person looking at a printed image of Venus.

\section{EXPERIMENT 2A}

Experiment 1 confirmed that the Venus effect occurs for a mannequin standing in a real room and for a photograph of the same scene. Therefore, we have extended the arena in which the effect can be studied from paintings to real scenes and photographs of a scene. Experiment 2A was designed to test the possible origin of the effect. It is plausible that observers always claim that what a person sees in a mirror is the same as what they themselves are seeing. To test this hypothesis, we took photographs in which a person was in front of a mirror but only in some cases was her face visible in the mirror. On the basis of the name of the effect, we call this person Venus. Depending on what is visible to whom, there are four scenarios. (1) $\mathrm{V}-\mathrm{O}+$ : The person in the photograph (Venus) cannot see her own face, but the observer can. This scenario closely resembles many images representing a toilet of Venus, as was discussed in the introduction. (2) $\mathrm{V}+\mathrm{O}-$ : The person in the photograph (Venus) can see her own face, but the observer cannot. This is interesting because observers may claim that Venus is not looking at herself if they incorrectly believe that what they see is the same as what Venus sees. (3) $\mathrm{V}+\mathrm{O}+$ : Both the person in the photograph (Venus) and the observer can see Venus's face in the mirror. This is possible when Venus is very near the mirror, the mirror is relatively large (i.e., larger than the face), and the observer sees the back of Venus's head. (4) $\mathrm{V}-\mathrm{O}-$ : Neither the person in the photograph (Venus) nor the observer can see Venus's face in the mirror. If the observers report that Venus can see herself in this condition, it would suggest that they overgeneralize and expect that a person can see him- or herself in a mirror whenever a mirror is in the vicinity of the person. This overestimation of what is visible would be consistent with the general overestimation of what is visible in a mirror documented in the literature (Bertamini, Latto, \& Spooner, 2003; Croucher et al., 2002).

\section{Method}

Participants. The participants were 88 members of the University of Liverpool community (63 female). Their average age was 21.9 years $(S D=7.4)$.

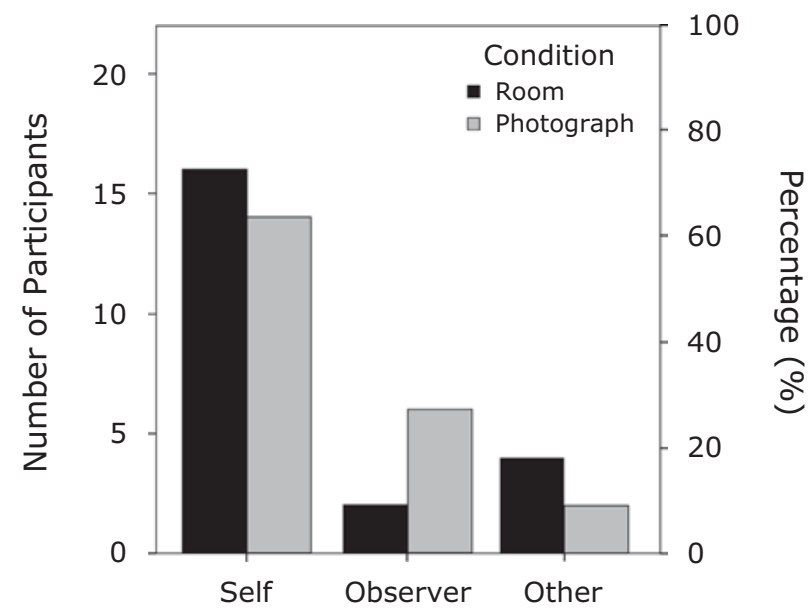

Response Category

Figure 3. Results from Experiment 1. There were 22 participants in each of the two conditions. The correct answer is observer. 
Materials. The participants were assigned to one of four groups ( $n=22$ in each). Each group was presented with one A4 sheet of paper showing a color photograph. The image showed a scene with a woman facing a mirror $(34.5 \times 49.5 \mathrm{~cm})$ in a room (see Figure 4$)$. The room was chosen because there was a square wooden frame on the wall where the mirror hung, which added extra cues about perspective to the observer looking at the scene. Another advantage of the room was that the door was positioned so that when it was open, it did not obstruct the view. So, unlike that in Experiment 1, the photograph was not taken through a window.

Figures 4 and 5 illustrate the four conditions that are generated by the factorial combination of two factors: Venus can or cannot see her own face $(\mathrm{V}+$ and $\mathrm{V}-$ ), and the observer can or cannot see Venus's face $(\mathrm{O}+$ and $\mathrm{O}-)$.

Procedure. The participants were asked the same questions as in Experiment 1, and the experimenter noted down all observations.

\section{Results}

The answers given by the participants were classified as in Experiment 1. We started with three categories: self if they described Venus as looking at herself in the mirror (correct for $\mathrm{V}+$ and incorrect for $\mathrm{V}$ - conditions), $o b$ server if they described Venus as looking at the observer or the camera taking the photograph, and other if the participants described Venus as being able to see parts of the room or just objects in the room.

In the $\mathrm{V}-\mathrm{O}+$ condition, 17 people stated that Venus was looking at herself (self), and 5 people stated that she could see them (observer). In the $\mathrm{V}+\mathrm{O}-$ condition, 16 people stated that Venus was looking at herself (self), and 6 people stated that she could see something else in the room (other). In the $\mathrm{V}+\mathrm{O}+$ condition, 20 people stated that Venus was looking at herself (self), and 2 people stated that she could see something else in the room (other). Finally, in the $\mathrm{V}-\mathrm{O}-$ condition, 19 people stated that Venus was looking at herself (self), and 3 people stated that she could see something else in the room (other). Figure 6 shows the response frequencies in the different conditions.

The main aspect of these data is that a clear majority of the participants in each condition claimed that Venus was looking at herself (between $73 \%$ and $91 \%$ ). A test was conducted to assess whether the self response was as frequent as the rest of the responses pooled. The self response was significantly more frequent than the other responses $\left[\chi^{2}(1)=19.82, p<.001\right]$.

To establish whether there was a sensitivity to the fact that Venus could see herself in some conditions and not in others, we performed a chi-squared test between the $\mathrm{V}-$ $(\mathrm{V}-\mathrm{O}-$ and $\mathrm{V}-\mathrm{O}+)$ and $\mathrm{V}+(\mathrm{V}+\mathrm{O}+$ and $\mathrm{V}+\mathrm{O}-)$ conditions with respect to the frequency of the self response ( $82 \%$ in both cases). No significant association was found $\left[\chi^{2}(1)=0.0\right.$, n.s. $]$.

To establish whether the participants were sensitive to the fact that Venus could see the camera/observer in some conditions and not in others, we performed a Fisher

Venus Can See Her Own Face
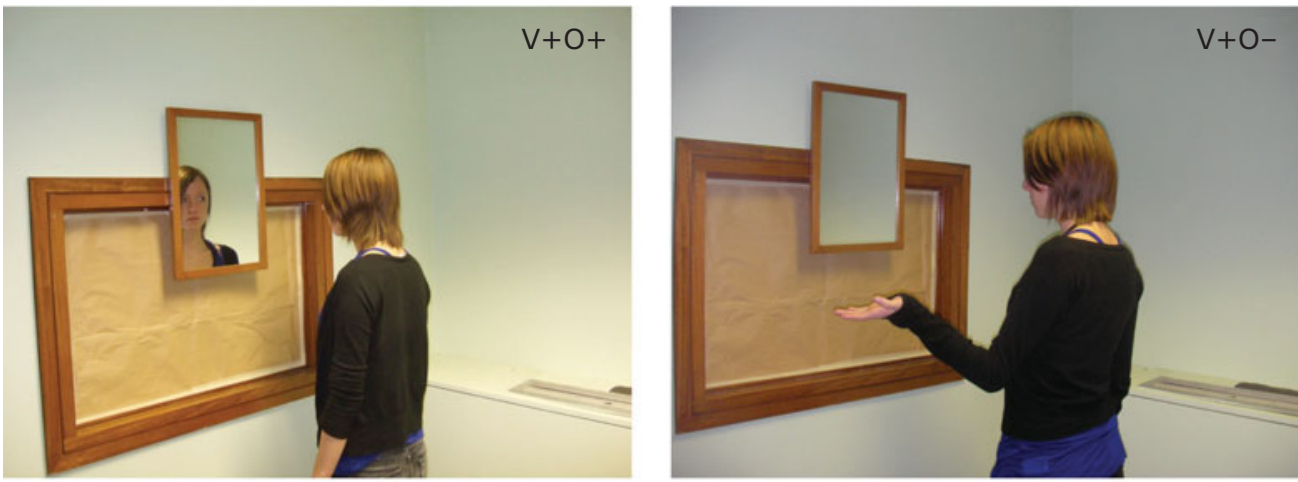

Venus Cannot See Her Own Face

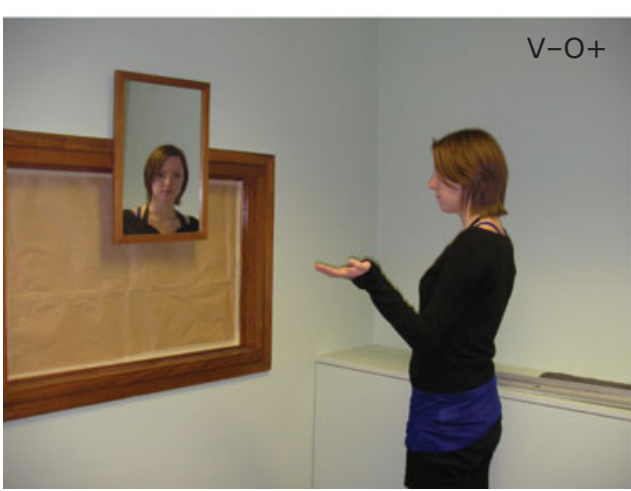

Observer Can See Her Face

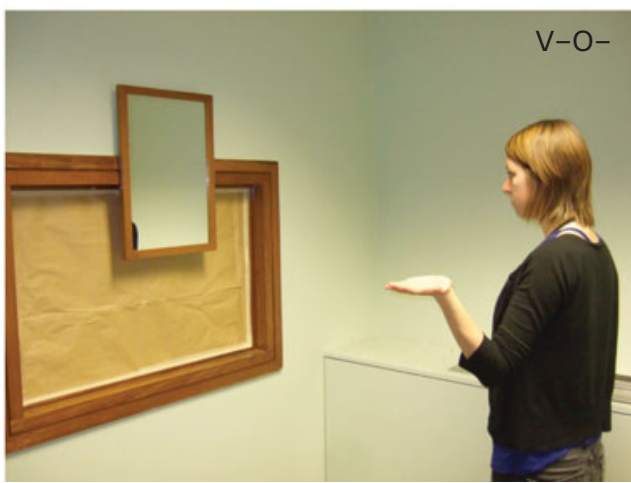

Observer Cannot See Her Face

Figure 4. Photographs used in Experiment 2A. The posture of the left arm was meant to match the posture of the mannequin used in Experiment 1, although this posture was abandoned in condition $\mathrm{V}+\mathrm{O}+$ because the hand would have been too close to the mirror. 

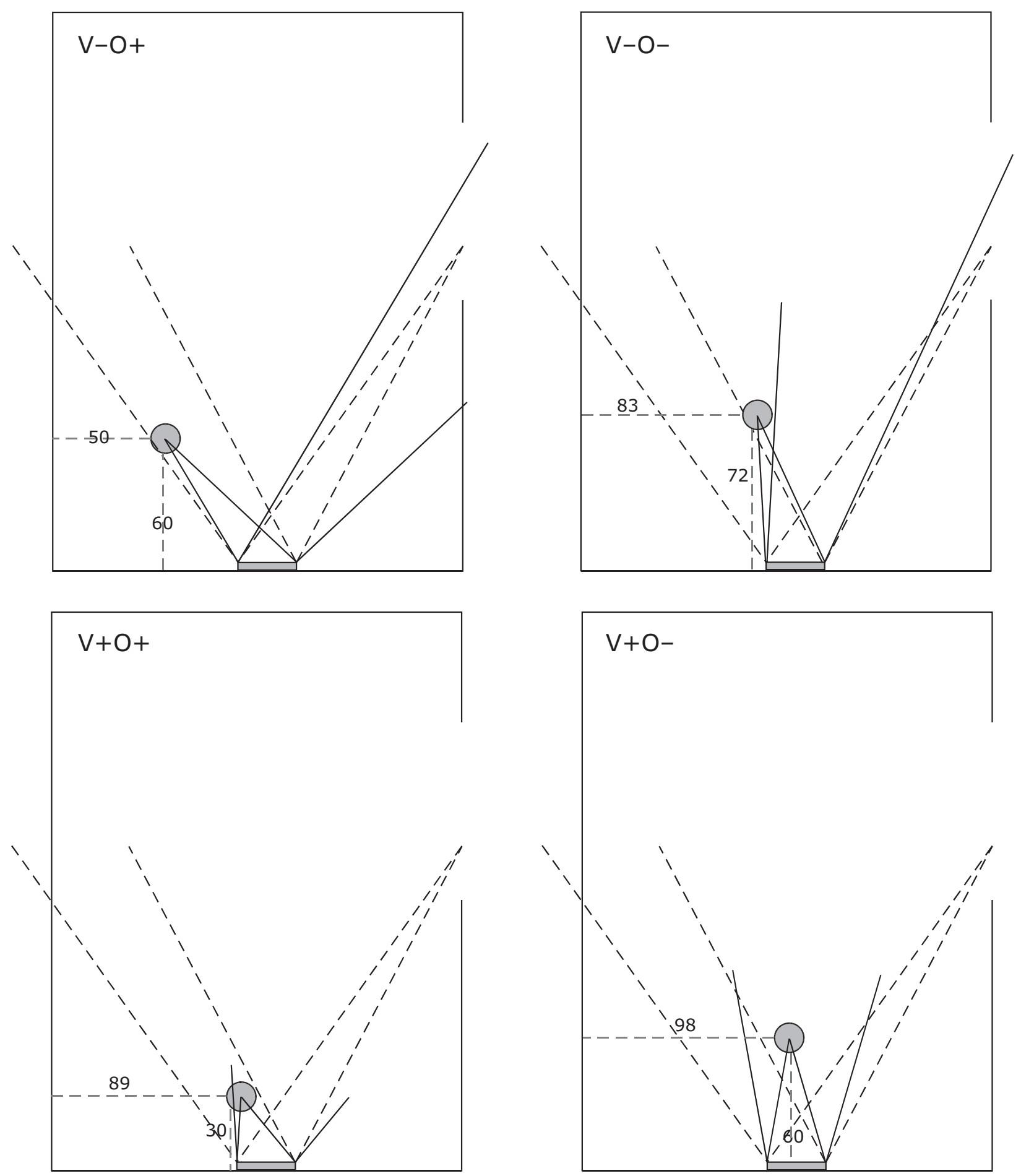

Figure 5. Diagrams of the room used in Experiment 2A. There were four possible locations for the person (Venus, represented by a gray disk) in the room. The lines with numbers give the distance (in centimeters) of Venus from two of the walls. The dashed lines show what was visible to the observer outside the door on the right, and the solid lines show what was visible to Venus.

exact test between the $\mathrm{O}-(\mathrm{V}+\mathrm{O}-$ and $\mathrm{V}-\mathrm{O}-)$ and $\mathrm{O}+$ $(\mathrm{V}+\mathrm{O}+$ and $\mathrm{V}-\mathrm{O}+)$ conditions with respect to the frequency of the observer response $(0 \%$ and $11 \%$, respectively). A significant association was found $(p=.027)$ :
The participants were more likely to respond observer when, in fact, Venus could see the observer in the mirror.

Finally, to establish whether there was a sensitivity to the fact that Venus could see only the reflection of the wall 


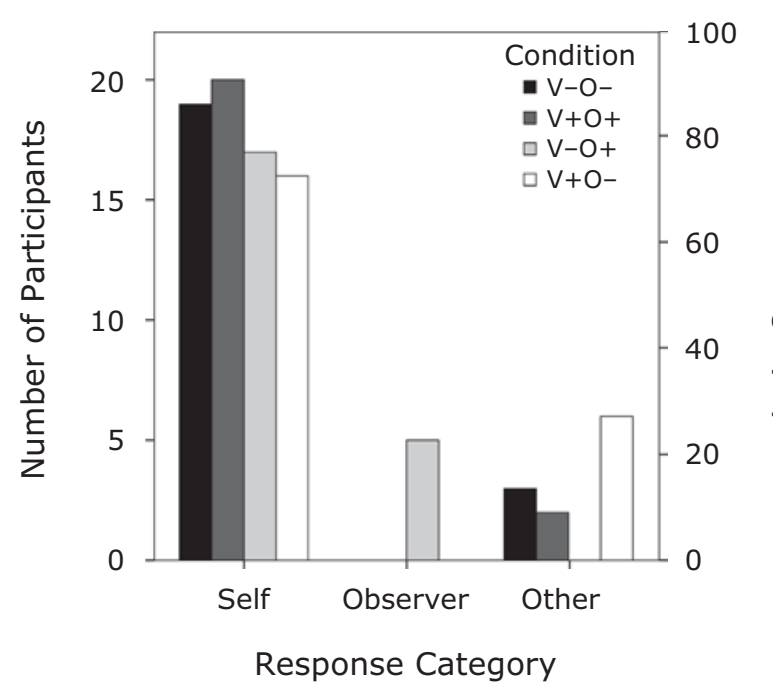

Figure 6. Results from Experiment 2A. There were 22 participants in each of the four conditions. Observer is the correct answer for $\mathrm{O}+$ conditions, and self is correct for $\mathrm{V}+$ conditions.

in one condition, we performed a Fisher exact test between that condition $(\mathrm{V}-\mathrm{O}-)$ and all of the others combined, with respect to the frequency of the other response (12\% and $14 \%$, respectively). No significant association was found $(p=.852)$. Note that the response that Venus saw the wall was actually most frequent in the $\mathrm{V}+\mathrm{O}-$ condition. This is a condition in which only a blank wall was visible in the mirror (from the participant's viewpoint), suggesting that their responses may have been biased to some extent by what was visible to them in the mirror.

In summary, first, the Venus effect was not restricted to cases in which the face of Venus was visible in the mirror to the observer (the number of self responses was never lower than 70\%). Second, some participants did seem to realize that since they could see Venus in the mirror, Venus would be able to see the camera/observer, and so they correctly responded observer. This significant group was nonetheless a minority.

\section{EXPERIMENT 2B}

We decided to collect more observations using the same procedure as that in Experiment 2A, but with the addition of a new question. We asked participants whether they thought that Venus was in front of the mirror or to the side. This information is particularly important, in conditions in which there is a Venus effect, for testing whether the incorrect response (she can see herself) is due to a misperceived location of Venus. If the participants say that she can see herself but also that she is in front of the mirror, the effect may be due in large part to the ambiguity in the photograph with respect to the layout. We used the $\mathrm{V}-\mathrm{O}+$ image from Experiment 2A. In addition, for half of the participants, we removed the image of the face from the mirror and replaced it with an image of the wall. This was done to see whether the presence of the face is used by participants to infer that Venus is on the right side of the mirror.

\section{Method}

Participants. The participants were 30 members of the University of Liverpool community ( 28 female). Their average age was 20.4 years $(S D=6.2)$.

Materials and Procedure. The participants were assigned to one of two groups ( $n=15$ in each). One group was presented with a sheet of paper showing the $\mathrm{V}-\mathrm{O}+$ photograph used in Experiment 2A (see Figure 4). The other group was presented with the same image manipulated to remove the face of Venus from the mirror. The procedure was the same as that in Experiment 2A, with the addition of a follow-up question. The participants were asked to judge the position of the woman in the room with respect to the mirror; specifically, they were asked to say whether she was in front of the mirror, on the left, or on the right.

\section{Results}

The answers given by the participants were classified as in Experiment 1. Overall, a clear majority of the participants said that Venus could see herself in the mirror (20), and there was no difference between the two versions of the scene (original and with face removed) with respect to the number of people who said that she could see herself $\left[\chi^{2}(2)=1.31\right.$, n.s.]. Therefore, we again conclude that the presence of a visible face in the mirror is not the main factor in generating the Venus effect.

The main reason for Experiment 2B, however, was to collect evidence about where in the room the participants thought that Venus was located. A majority correctly said that she was to the side of the mirror (22). Next, we looked at the relationship between the two responses (regarding whether Venus could see herself reflected in the mirror and her location in the room). Of the people who said that she could see herself, the majority correctly said that she was to the side of the mirror (14/20). This was also the case for the people who said that she could not see herself $(8 / 10)$. There was no difference between the two groups $\left[\chi^{2}(2)=\right.$ 1.28, n.s.]. This result is important because it shows that a mislocalization of Venus as standing in front of the mirror is not the reason for the Venus effect. Even for a simple photograph with few visible objects in the room, most of the participants correctly reported that Venus was to the side of the mirror.

A key aspect of these results needs emphasizing. A majority of our participants produced two responses that define an impossible situation: They claimed that Venus could see herself and that she was not in front of the mirror. Leaving the role of the photograph to one side, this is an illustration of the fact that people hold beliefs about mirrors that are at odds with their everyday experience.

\section{EXPERIMENT 3}

The verbal reports in Experiments 1, 2A, and 2B were often extremely brief. As soon as a participant said that Venus was looking at herself in a mirror, the experiment was terminated. In Experiment 3, we introduced a set of forced choice questions. This allows a test not only of how 
often people claim that Venus can see herself, but also of how often they say that Venus can see the observer when they are explicitly asked that question. A useful rule that observers could use is that when they see Venus's eyes in a mirror, Venus can see the observer in the mirror. We call this the eyes heuristic.

Two groups were tested in Experiment 3. One group was asked whether a person in a photograph (Vince, a male Venus) could see the observer in the mirror (the V-sees-O task). The other group was asked whether Vince could see himself in the mirror (the $\mathrm{V}$-sees- $\mathrm{V}$ task). The two groups were shown the same six photographs, in which the distance of the camera's viewpoint from the mirror (near or far) and the position of Vince relative to the mirror (in front of the mirror, opposite the far edge of the mirror, or opposite the wall to the right of the mirror) were varied.

Two of the photographs showed Vince's face reflected in the mirror. The eyes heuristic predicts that for the $\mathrm{V}$-sees-O task, the participants should correctly state that
Vince could see the observer reflected in the mirror for these situations, but not for the other four scenes.

The original description of the Venus effect (Bertamini, Latto, \& Spooner, 2003) predicts instead that the participants should incorrectly say that Vince could see himself for these two photographs, but not for the other four scenes. In fact, Vince could fully see himself only when he was in front of the mirror, but he could see part of his face when he was opposite the edge of the mirror. If the Venus effect reflects people's failure to take into account the effect of the difference in viewpoint between themselves and Vince, as was demonstrated in Experiment 2A, people will tend to say yes in the $\mathrm{V}$-sees- $\mathrm{V}$ task for almost all stimuli.

\section{Method}

Participants. The participants were 290 volunteers ( 211 female) attending Open Days at the University of Liverpool. Their average age was 30.5 years $(S D=13.6)$. One group $(n=170)$ performed the V-sees-V task, and another $(n=140)$ performed the V-sees-O task.
Center Position Vince Can See His Own Face

Edge Position Vince Can See Part of His Face

Wall Position Vince Cannot See His Own Face
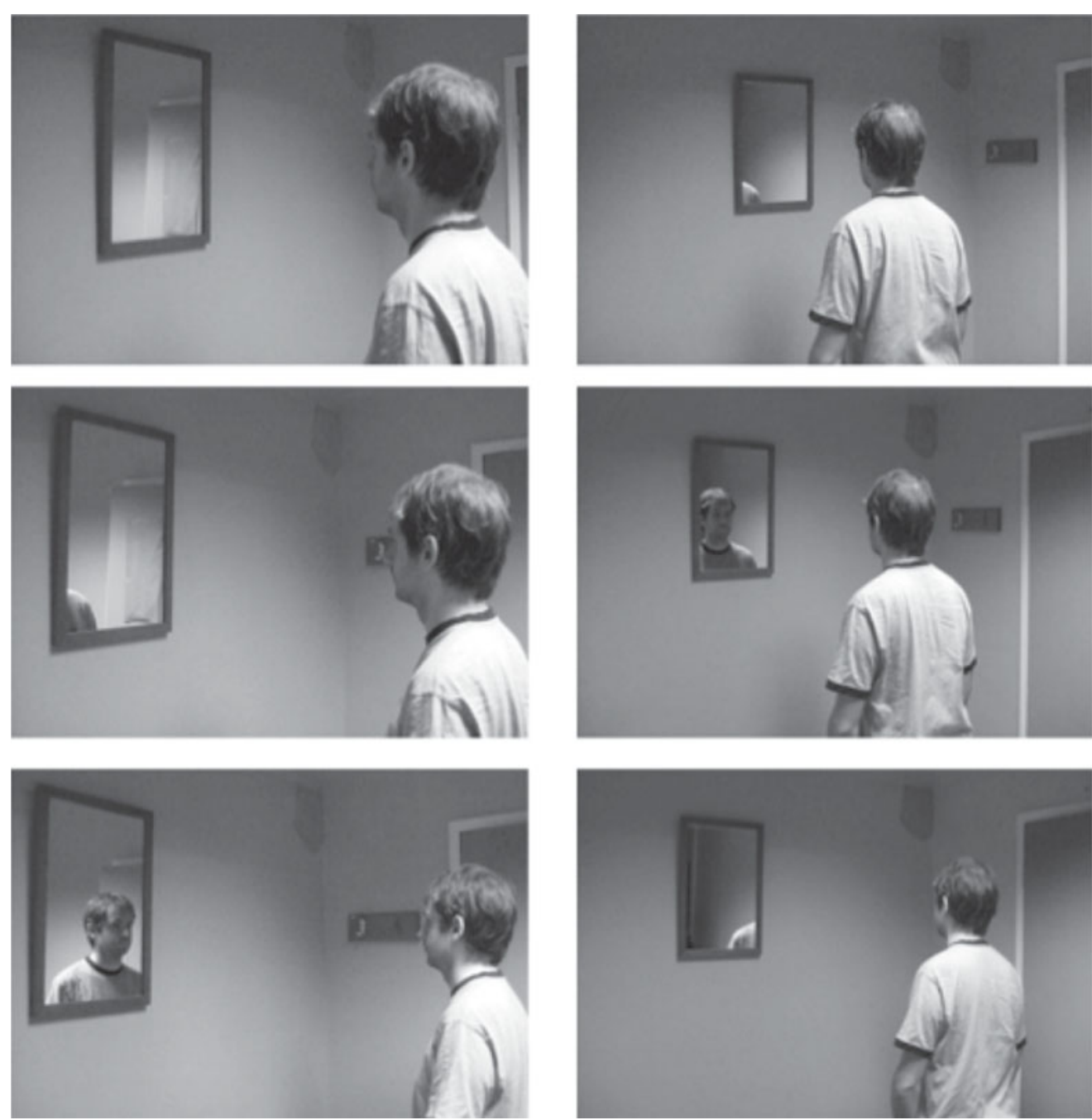

Camera Near

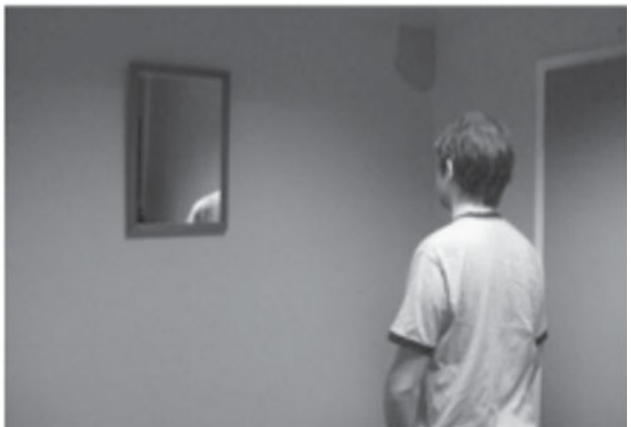

Camera Far

Figure 7. The six photographs used in Experiment 3. 

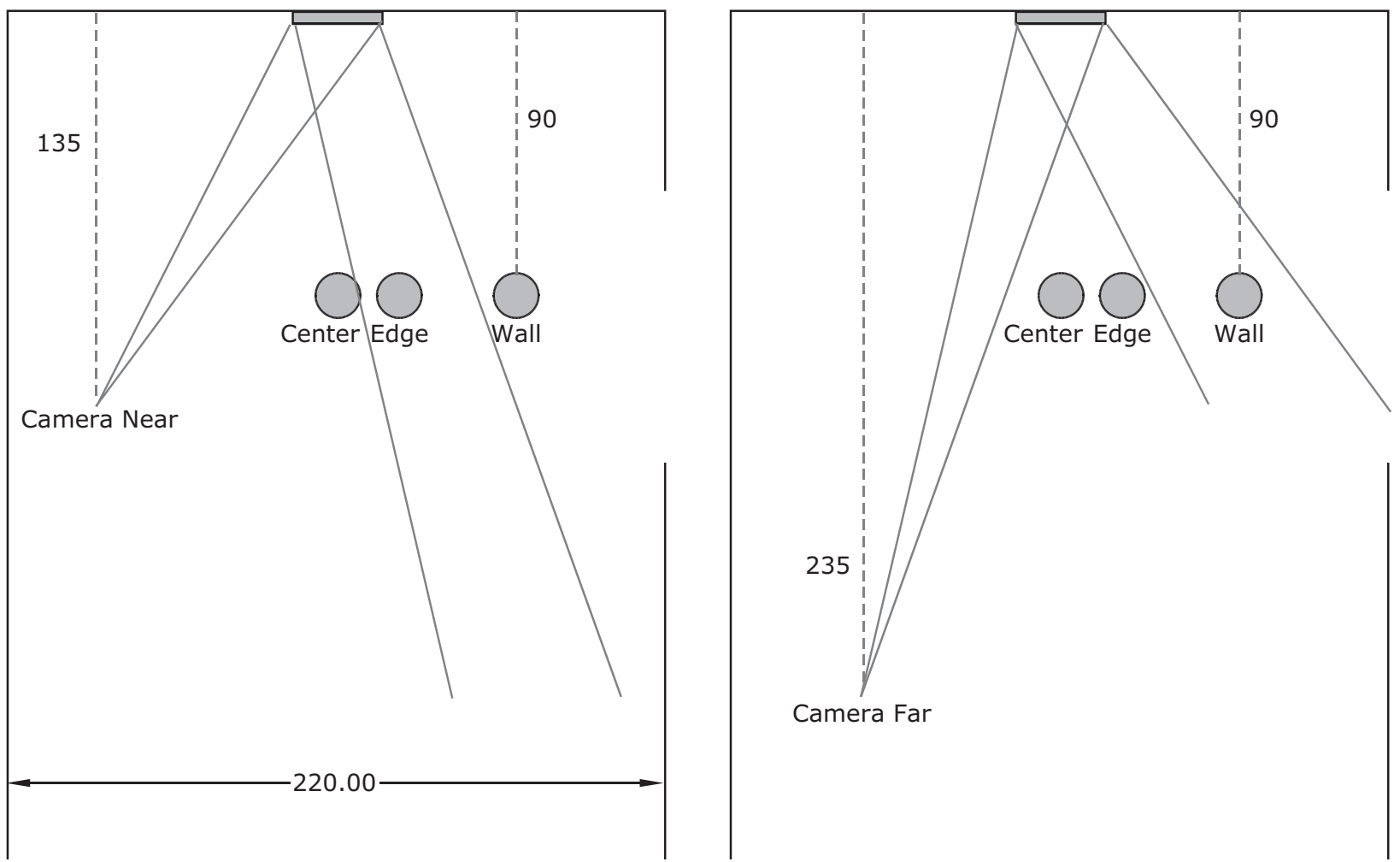

Figure 8. Diagram of the room used in Experiment 3. The camera was either in the near (left panel) or in the far (right panel) position. The person was in one of three positions relative to the mirror (center, edge, wall).

Materials and Procedure. The participants were tested in a large lecture theatre. Each person was given a booklet including several tests. The stimuli (Figure 7) were printed on a single page and comprised six grayscale photographs of a room. Figure 8 illustrates the layout of the room. Each photograph showed a rear view of a male subject, Vince, looking toward a mirror. The photographs were taken from two camera positions: nearer or farther away from the mirror. Three photographs were taken from each of these two camera positions, with Vince standing in front of the middle of the mirror, in front of the right edge of the mirror, and to the right of the mirror in front of the wall (Figure 8). These three positions will be referred to as the center, edge, and wall positions, respectively. Vince was not visible in the mirror reflection shown in the near/center photograph. Part of Vince's body was visible in the other photographs, but his face was visible only in the near/wall and the far/edge photographs. The six photographs were presented to the participants in four different orders to counterbalance presentation.

The V-sees-O group decided whether Vince could look into the mirror and see whether the observer was wearing sunglasses. The V-sees-V group decided whether Vince could see his own face in the mirror. There were between 32 and 39 participants in each of the four counterbalancing orders within each group. The participants circled the yes, no, or don't know response for each of the six photographs.

\section{Results}

The V-sees-O task. The correct response for the $\mathrm{V}$-sees-O task was yes when Vince's face was visible (in the near/wall and the far/edge photographs) and no otherwise. Figure 9 shows that most people answered yes to these two images $(82 \%$ and $84 \%$, respectively; above chance in both cases, $z$ tests' $p=.004$ and $p=.003$, re- spectively). However, this may be a bit misleading, because most of them also produced a yes to at least some of the other images. The correct pattern of responses (no, no, no, yes, yes, no) was produced by only 45 of the 140 individuals $(32 \%)$. Therefore, many people do not know that if and only if they can see someone in a mirror, can that person see them, even when they are explicitly asked to consider whether the person can see the observer.

The V-sees-V task. Vince could see himself in the center position and could see part of his face in the edge position. Just 3 of the 170 participants $(2 \%)$ produced a pattern of results based on the principle that Vince sees what the observer sees (no, no, no, yes, yes, no). In other words, few of the participants thought that Vince could see himself in the mirror if and only if they could see Vince in the mirror. The most common response was that Vince could see himself in every case (yes, yes, yes, yes, yes, yes; 23 of 170 responses, $14 \%$ ). In this sense, the presence of the face in the mirror as seen in the photograph was not a strong predictor of what people say. Nevertheless, let us take each position in turn.

When Vince was in front of the mirror (center), the participants could work out that he could see himself, but only when the camera was far and provided plenty of information about the fact that he was right in front of the mirror $(38 \%$ vs. $73 \%$ in the near and far conditions, respectively). When Vince was at the edge of the mirror, there were more yes responses for the far position $(82 \%)$ than for the near position (72\%), and the far position was 
V-Sees-O $(n=140)$

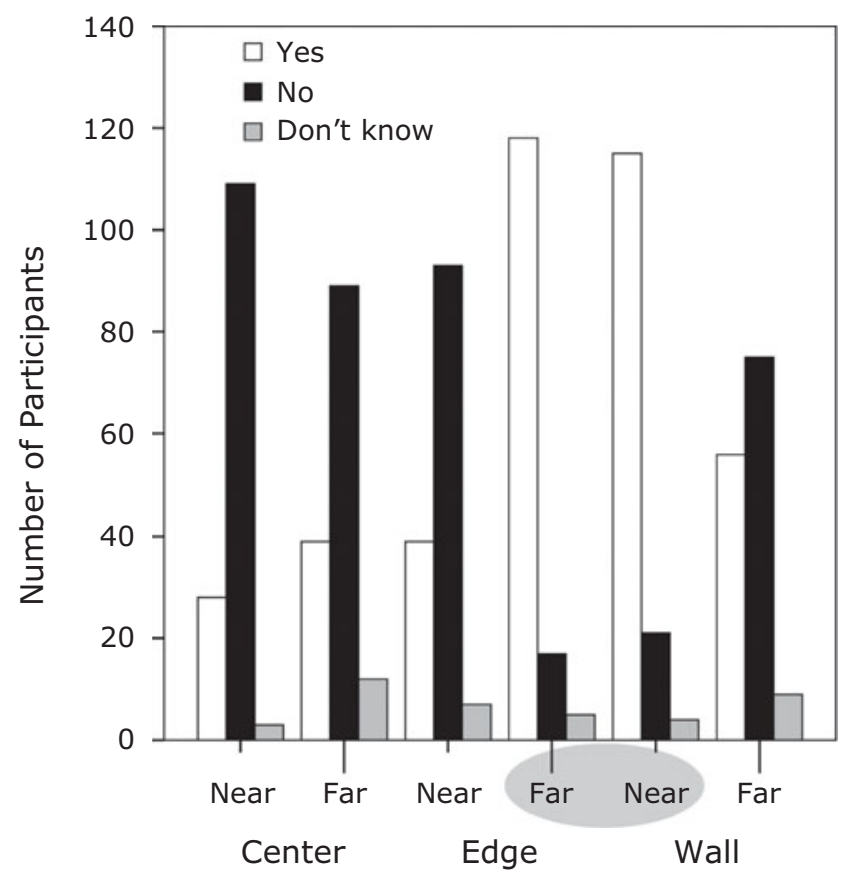

V-Sees-V $(n=170)$

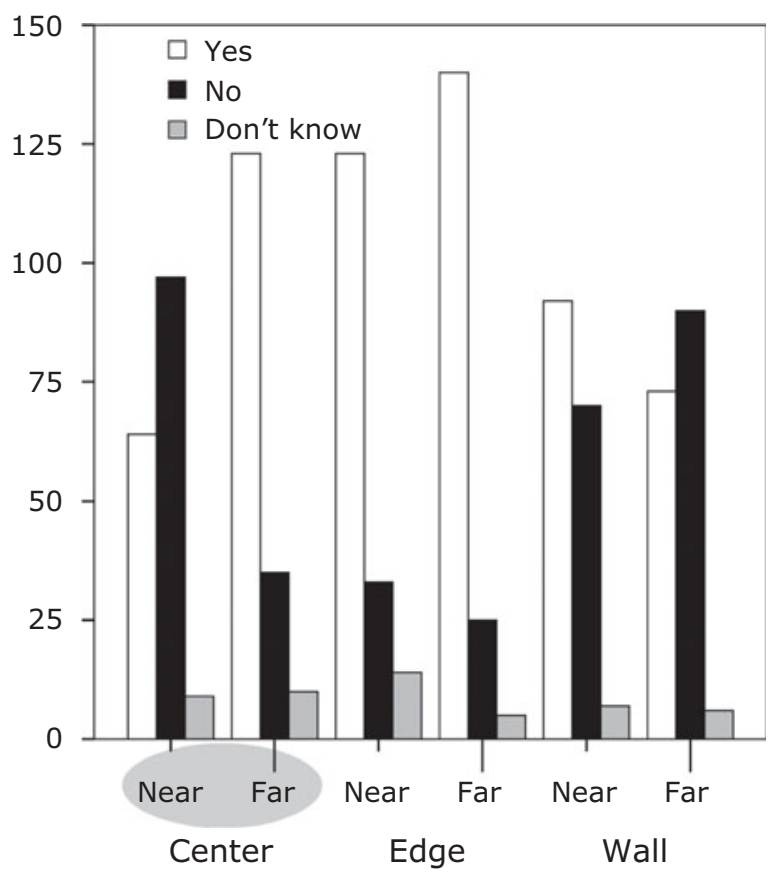

Figure 9. Results from Experiment 3. Each participant saw a set of six photographs (see Figure 7) in counterbalanced order. The correct answer in the V-sees-O task was to say yes in the near/wall and the far/edge cases, and these two conditions have been marked with a gray ellipse for this reason. In the $V$-sees-V task, Vince could see himself in the center position, and these two conditions have been marked with a gray ellipse. Vince could also see part of his face in the edge position.

the one from which the face appeared in the mirror. By contrast, when Vince was near the wall, there were more yes responses for the near position $(54 \%)$ than for the far position (43\%), and the near position was now the one from which the face appeared in the mirror. We analyzed the two positions in which the face was present or absent (edge and wall) to confirm the association between the yes response and the camera location. Because, unlike in Experiment 2A, our observations are not independent, we used the McNemar change test $\left[\chi^{2}(1)=9.52, p=.002\right]$.

In summary, there was a tendency to say that Vince could see himself from most positions, whether or not his face was visible. This is at odds with the original description of the Venus effect, which suggested that the reason people claim that Venus can see herself is because they can see her face reflected. But, although not necessary or sufficient, the presence of Vince's face in the mirror did seem to increase the observers' belief that Vince could see himself in the mirror.

\section{EXPERIMENT 4}

In Experiment 4, participants were shown two images and were correctly informed that in one scene, it was possible for the man to see his face reflected in the mirror. In the other scene, he could not see himself in the mirror. They were then asked to select the scene in which it was possible. This forced choice task (2AFC) was more constrained than those used in the previous experiments, in which the participants were given no guidance as to how many of the scenes showed a situation in which Venus or Vince could see themselves. One possibility was that the error would disappear in this situation, in which the participants directly compared two scenes and perhaps adopted a more analytical approach. On the other hand, some people might still make errors in this task if they thought that Vince could see himself equally well in the two scenes.

Performance on this $2 \mathrm{AFC}$ task was contrasted with performance on a matched $4 \mathrm{AFC}$ task in which the participants could respond that the man could see himself in neither or in both of the scenes, as well as in only the left one or in only the right one. If the participants changed their response in the 4AFC and selected the option that the man could see himself in both scenes, this would be consistent with the most common error made in Experiments 1-3.

In Experiment 4, we introduced a new set of photographs in which the feet of Vince were visible. This made Vince's location with respect to the mirror clear. In addition, Vince's locations on the floor were marked with crosses, again clarifying the spatial layout. Vince was photographed in front of the mirror or to the right of the mirror and at two distances from the mirror, giving a total of four scenes (Figure 10).

\section{Method}

Participants. The participants were 328 volunteers (223 female) attending Open Days at the University of Liverpool. Their average 
Vince Stands in Front of Mirror and He Can See His Own Face

\section{Vince Stands to the Right of Mirror and He Cannot See His Own Face}
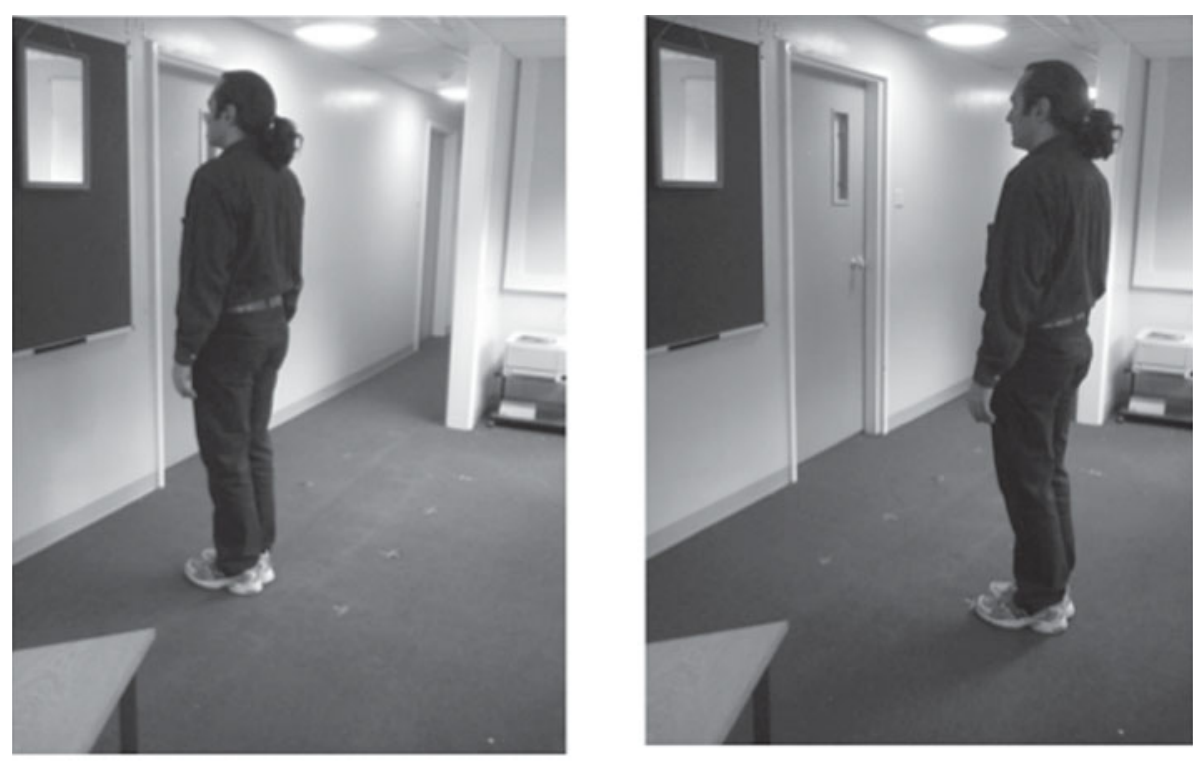

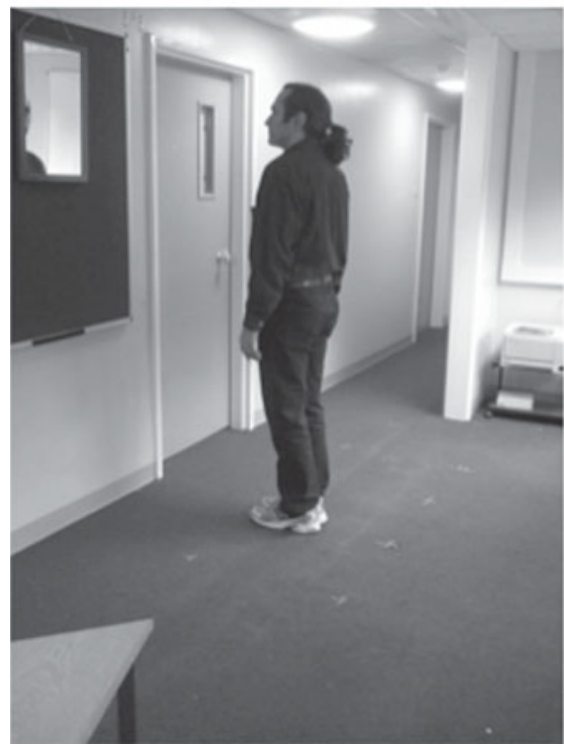

Vincent Near

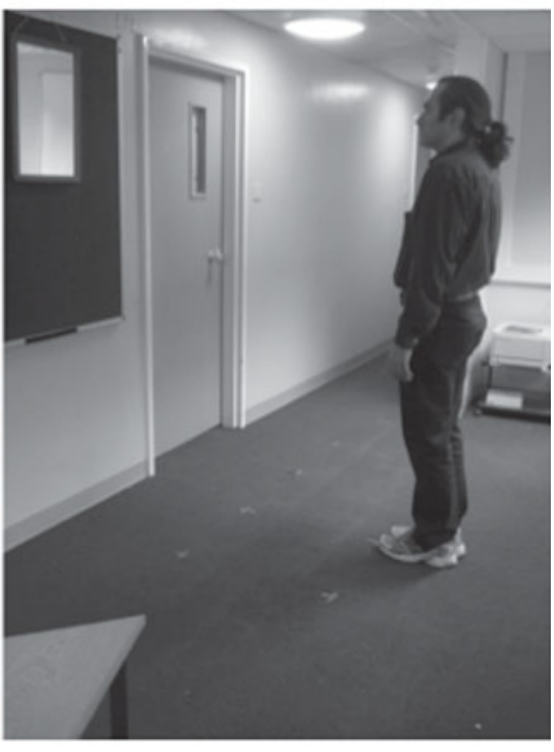

Vincent Far

Figure 10. The four photographs used in Experiment 4. The participants were shown either the two Vince near or the two Vince far scenes.

age was 32.5 years $(S D=15.9)$. One group $(n=175)$ saw the pair of stimuli in which Vince was nearer the wall, and another group $(n=153)$ saw the pair of stimuli in which Vince was farther from the wall (see Figure 10).

Materials and Procedure. The participants were tested in a large lecture theater. They were shown two photographs of a rear view of a male subject, Vince, looking toward a mirror. Vince's face was never visible in the mirror. In one scene, Vince could see himself because he was standing in front of the mirror, and in the other he could not, because he was standing to the right of the mirror (Figure 10). Left and right positioning of these two scenes was counterbalanced across participants. The procedure was the same as that of Experiment 3.

Within each group of participants (Vince near and Vince far), there was a further subdivision into two subgroups. One group $(n=$
174) did the $2 \mathrm{AFC}$ task followed, on a separate sheet, by the $4 \mathrm{AFC}$ task. The other group $(n=154)$ did only the 4AFC task.

For the 2AFC tasks, the participants had to circle one of two options: whether Vince could see himself in the left or the right photograph. For the 4AFC task, the participants were given four alternatives and were asked to circle one: whether Vince could see himself in neither photograph, in only the left, in only the right, or in both photographs.

\section{Results}

Most of the participants answered correctly in the $2 \mathrm{AFC}$ task $(80 \%$ and $75 \%$, respectively, in the near and far conditions; see Figure 11). After correction for guessing, these values were $61 \%$ and $49 \%$, respectively. Perfor- 

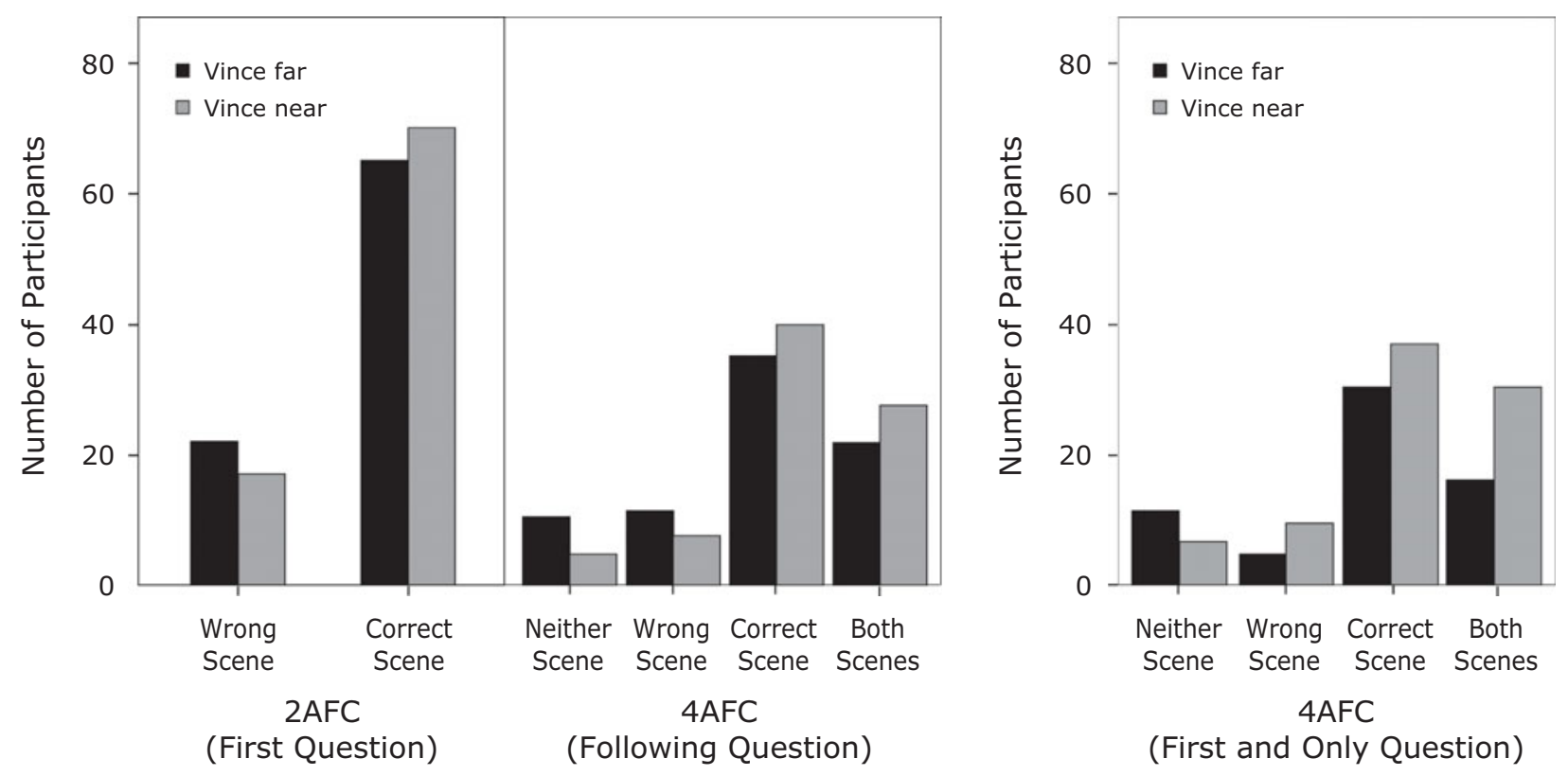

Figure 11. Results from Experiment 4. Each participant saw a pair of photographs (see Figure 10), and only in one of them could Vince see himself in the mirror. For one group (on the left) the 2AFC task was followed, on a separate sheet, by a 4AFC task. The other group (on the right) did only the $4 \mathrm{AFC}$ task.

mance was, therefore, above chance (binomial test, $p<$ .001) but far from perfect. These participants were then given the 4AFC task to see whether they responded both scenes when given the option, as we expected on the basis of our earlier results. Figure 11 shows that fewer than half of these participants responded correctly in the 4AFC task (47\%). As was predicted, this was largely because $31 \%$ said that Vince could see himself in both scenes.

However, one possibility is that when the participants were given a second chance to do the task, they reasoned that this meant that one of the two new response alternatives must be correct, and this may have biased their responses. To test this hypothesis, we included in the design a second group of participants who responded only to the 4AFC task. As can be seen in Figure 11, in this group, the distribution of responses was remarkably similar to that of the group that responded to both the $2 \mathrm{AFC}$ and the $4 \mathrm{AFC}$ questions [a chi-squared test confirmed no difference between the two groups; $\chi^{2}(9)=10.41$, n.s.]. The percentage of participants who chose the correct scene was $46 \%$, and $32 \%$ chose the option of saying that Vince could see himself in both scenes. We take this as evidence that these proportions are not specific to one procedure; instead, they reflect the fact that for many of the participants, Vince did not need to be in front of a mirror to see himself. This may be surprising but is entirely consistent with the documented early error in the literature (Bertamini, Latto, \& Spooner, 2003; Croucher et al., 2002). For instance, in Croucher et al., there were three groups of responses that appeared across all of the experiments: Few people thought that a person can see herself in a mirror as soon as the mirror is visible to her; $40 \%-50 \%$ correctly expected that the person had to reach the near edge of the mirror, and $30 \%-50 \%$ placed their responses too early but not as soon as the mirror was visible. In this last case, the person would have been to the side of the mirror in a position similar to that of Vince when not in front of the mirror in Experiment 4 (and similar to that of Venus in Velasquez's painting).

\section{EXPERIMENT 5}

Experiment 5 was designed to quantify participants' perception of the extent of what a mirror shows to an observer. The participants saw a diagram with a person in front of a mirror, and we asked how much of the room behind her she would be able to see. We did that by asking the participants to circle all of the nails in the back wall that this person could see. The person was depicted as standing to the right of one end of the mirror, at the center of the mirror, or to the left of the other end of the mirror (see Figure 12).

Let us consider what we can learn from this task. First of all, if participants can deal with this task without major difficulties, they will be able to describe which portion of the room is visible to the observer. Therefore, for a person on the left of the mirror, they will say that he or she can see the right corner of the room. If the difficulty is purely about precision, the answers will be on average correct, but with some variability. A second possibility is that the participants will claim that a person on the left would see the left corner of the room, and vice versa, because the left side of the room is expected (incorrectly) to be on the right side of the virtual world (for more on this rotation hypothesis, see Bertamini, Spooner, \& Hecht, 2003). A third and final possibility is that the participants will claim that what is visible in a mirror located in the center of the room is mainly the center of the room but extends to a 

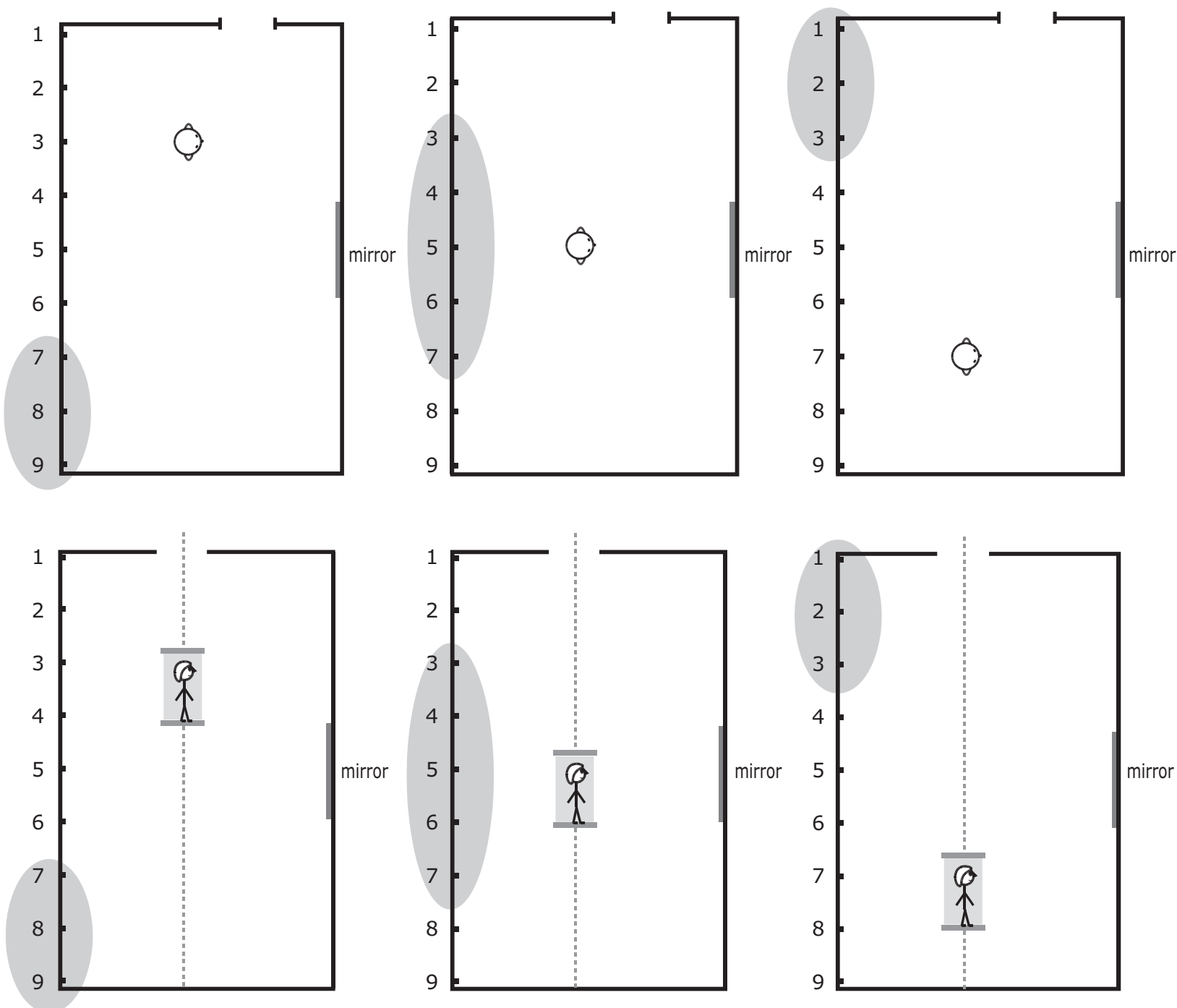

Figure 12. Stimuli used in Experiment 5. There were three horizontal conditions (top panel) and three vertical conditions (bottom panel). The gray ellipses cover the nails that were the correct answers. These ellipses were not present in the experimental stimuli.

wider area than the size of the mirror itself (a visibility cone specific to a given mirror). This means that what is believed to be visible does not depend on the location of the viewpoint. If so, the location of the person in relation to the mirror should make little difference to the pattern of responses concerning the extent and number of nails that are visible in the mirror.

Experiment 5 included a horizontal and a vertical condition. They were identical, except that one was a top view of a room, and the other presented a side view with a person inside an elevator. They were included because, with respect to the early error, participants predict that they can see themselves early in the horizontal condition, but not in the vertical condition (Croucher et al., 2002).

\section{Method}

Participants. There were 66 participants ( 40 female). All of the participants were students of the University of Liverpool. One group $(n=35)$ saw the vertical stimuli, and the other $(n=31)$ saw the horizontal stimuli. Their mean age was 19.9 years $(S D=2.84)$.

Materials and Procedure. Figure 12 shows examples of the horizontal and vertical stimuli. The participants received either the horizontal or the vertical paper-and-pencil task. In the horizontal condition, the participants were shown three diagrams of a person standing in a room and to the left of the mirror, to the right of the mirror, or directly in front of the center of the mirror. On the wall behind the person were nine nails numbered 1 at the left to 9 on the right. In the vertical condition, the participants were shown three diagrams of the person in an elevator. In the three images, she was shown standing above the mirror, below the mirror, or in front of the center of the mirror. On the wall behind the person were nine nails numbered 1 at the top down to 9 at bottom.

The participants were asked to indicate which nails the person could see in the mirror. The correct nails for the position on the left (or above) are the nails numbered 7,8, and 9, and for the position on the right (or below), they are Nails 1, 2, and 3 (see Figure 12).

The test was administered in a classroom at the end of a lecture. The experimenter verbally issued instructions. The specific instructions were also printed at the bottom of the test pages - for instance, 
She is in a room and is looking at the mirror on the wall. On the back wall of the room are some nails, as numbered in the diagram. Please circle all the nails (numbers) that she can see in the mirror from where she is (she is free to look around as much as she likes).

\section{Results}

The data for the horizontal and vertical conditions are shown in Figure 13. The central nails tended to be selected, with a large overlap between responses in the left, right, and center conditions.

We counted the participants with correct answers according to a strict definition (all and only the visible nails selected). Few participants met this criterion. In the horizontal condition, the correct pattern of responses was produced by 0,1 , and 4 participants in the left, right, and center conditions, respectively. In the vertical condition, the numbers were 1, 1, and 4 in the left, right, and center conditions, respectively.

Next, we asked whether the participants selected too many nails. In the horizontal condition, the mean number of nails selected for the left and right positions combined was 4.3, which was higher than the correct number of $3[t(30)=5.39, p=.001]$. In the horizontal center position, the mean was 5.4, and the correct number was $5[t(30)=0.68$, n.s. $]$. In the vertical condition, the mean number of nails selected for the above and below positions combined was 4.2, which was higher than the correct number of $3[t(34)=4.68, p=.001]$. In the vertical center position, the mean was 3.8 , which was lower than the correct number of $5[t(34)=-3.46, p=.001]$.

The most important aspect of the data was their symmetry about the center of the mirror. To test the deviation from symmetry in the responses, we computed a weighted sum. Each nail was coded as negative (starting at -4 to the left or top) or positive (starting at 4 to the right or bottom). If the choices were symmetrical, the mean would not differ from 0 . In the horizontal condition, the means were $1.8,0.0$, and -1.3 for the left, center, and right stimuli, respectively. Although there was a trend for a shift toward negative and positive values for the left and right stimuli, respectively, these trends did not reach significance $[t(30)=1.87, t(30)=-1.46$, and $t(30)=-0.17$, respectively for the above, center, and below stimuli; all n.s.]. In the vertical condition, the means were $1.5,-0.2$, and -1.4 for the above, center, and below stimuli, respectively. Again, although there was a trend for a shift toward negative and positive values for the above and below stimuli, these trends did not reach significance $[t(34)=1.97$, $t(34)=-1.63$, and $t(34)=-0.66$, for the above, center, and below stimuli, respectively; all n.s.].

On one hand, the wider distributions of what is visible for the horizontal than for the vertical condition (Figure 13) were in the direction predicted by previous findings, because the early error is confined to horizontal conditions (Croucher et al., 2002). On the other hand, the answers were similar and symmetrical in both the horizontal and the vertical condition. Perhaps the dynamic nature of the early error task is critical for a heuristics based on the eye plane reaching the height of a vertical obstacle, as was argued in Jones, Bertamini, and Spooner (2010). We will not discuss this idea in detail here, because this aspect of the results is not the focus of the present study.

Overall, the results of Experiment 5 showed that the location of the viewpoint did not influence responses to the extent that would be predicted on the basis of the geometry of the situation. There was a trend for the responses to be shifted (correctly) in the direction opposite the location of the person in the photo, but there was a high tolerance to include nails that would not be visible in all three locations. More importantly, the responses were roughly symmetrical for the three locations, and the extent of what was judged to be visible was comparable, even though in reality, a larger number of nails would be visible from the central location.

These results help us in interpreting the data from the other experiments. We have suggested that the Venus effect originates from a difficulty in understanding that Venus's viewpoint is critical in determining what she can see in a mirror. In Experiment 5, the exact location of the person in front of the mirror was provided with a top-down view. Note that completely different parts of the room were visible from Venus's three different locations within the horizontal and vertical scenes. Nevertheless, the participants responded as if a similar central portion of the room was visible to a person located somewhere in the proximity of the mirror.

\section{DISCUSSION}

Experiments 1 and $2 \mathrm{~A}$ have in common the fact that we have analyzed spontaneous descriptions of a scene containing a mirror. Within these descriptions, most participants claimed that a person in a room (Venus) was looking at herself in a mirror. We found no evidence of a difference between a real-life setup and a pictorial condition (Experiment 1). This indicates that paintings with Venus as a subject are not a special situation, and the Venus effect as a phenomenon is not something unique to works of art.

In Experiment 2A, we used four photographs. The four conditions were generated by the factorial combination of two variables, whether Venus could see her own face in the mirror and whether the observer (or the camera) could see Venus's face in the mirror. In all conditions, the most common answer was that Venus could see herself. Therefore, it seems that as long as Venus is near a small mirror, people draw the conclusion that she must be looking at herself, whether her face is visible to them in the mirror or not. The observers might assume that if Venus is looking at a mirror, she is using that mirror to look at herself. This goes against the original description of the Venus effect, in which the implication was that observers claim that Venus sees the same image in the mirror that they see.

In Experiment 2B, we added a question about the perceived location of Venus in the room. Most participants, including a majority of those who said that Venus could see herself in the mirror, correctly stated that Venus was not in front of the mirror but to the right side, indicating that their error about what Venus could see was not simply 


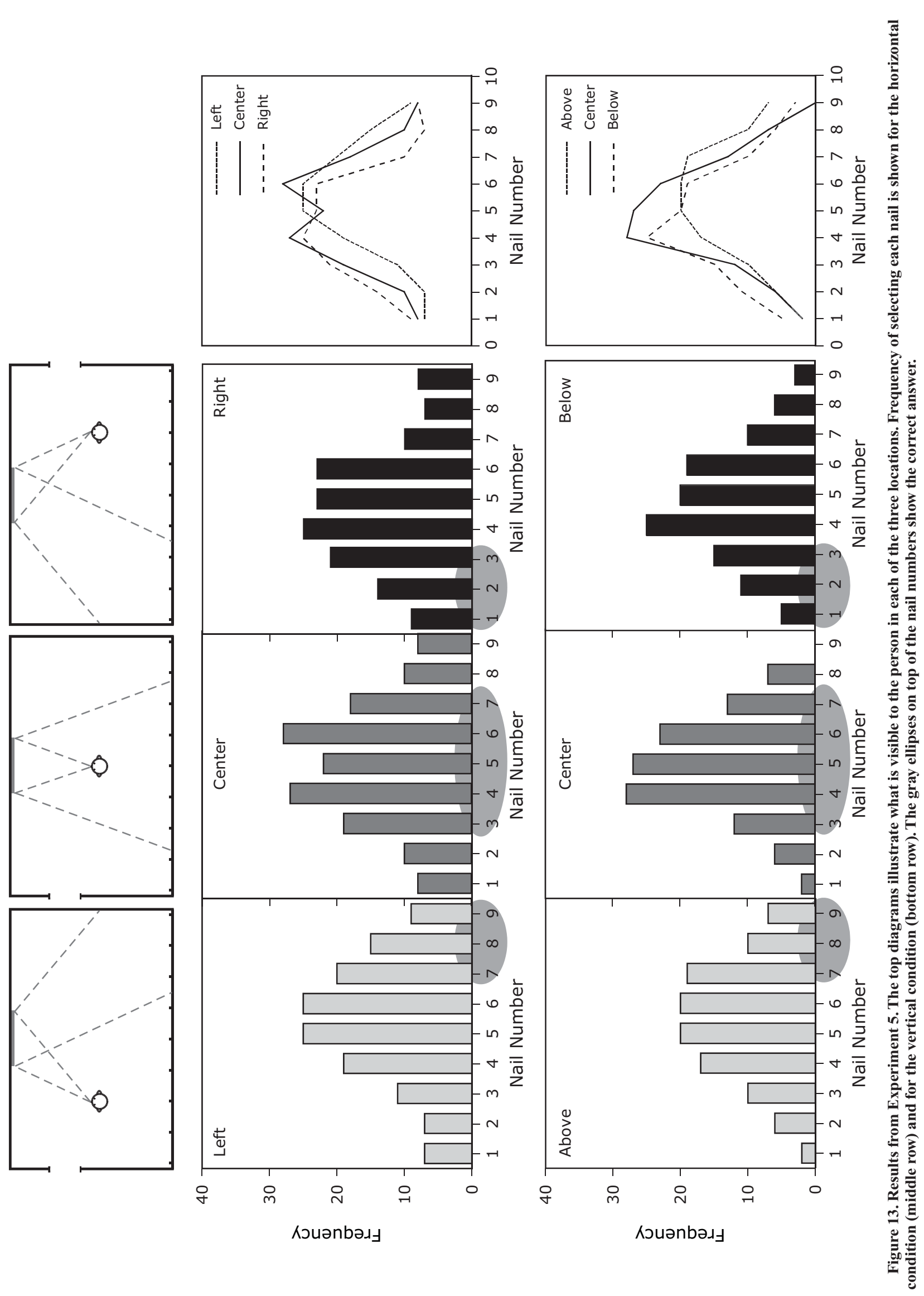


due to their misperceiving her location. In other words, a majority of the participants described a situation in which Venus was looking at herself and not in front of the mirror, something that is impossible.

In Experiment 3, we extended Experiment 2B with a different model (male instead of female), a different room, different locations for the camera and, most importantly, a change in how the question was asked. Each participant was presented with a set of photographs and was asked forced choice questions about what the person in the photo (Vince) could see. One group was asked whether Vince could see himself; another group was asked whether Vince could see the observer. Open questions and forced choice questions have different strengths and weaknesses, so Experiments $2 \mathrm{~A}$ and 3 complement each other.

Experiment 3, in agreement with Experiment 2A, confirmed that participants believed that Vince could see himself in most of the photos. The most common response was to say yes to every picture. This comprised only $15 \%$ of the responses, but the participants might have expected the experimenter to provide a set of photos with a mixture of correct yes and no responses. The level of yes responses would probably be higher if we had tested the stimuli individually, as was indeed the case in Experiment 2A. Another interesting aspect of Experiment 3 is the demonstration that although the most common response was that the model could see himself, this response was relatively more frequent when the face was visible in the mirror.

The photographs in Experiments $2 \mathrm{~A}$ and 3 were simple and uncluttered, they were not doctored in any way, and both tasks were straightforward (open question and multiple choice). The answers, on the other hand, suggest that the observers could not predict what the model could see in the mirror. Note that when asked open questions, the participants never complained that the images were ambiguous. The task was difficult, in the sense that there were many errors, but not in the sense that the participants did not understand the question that was being asked. This is a feature of the Venus effect: Observers have the spontaneous impression that Venus looks at herself, and this is not because of pressure to respond to an ambiguous image. ${ }^{2}$

Experiment 4 was similar to Experiment 3, in that participants were asked to make a forced choice response. We also used new photographs that included markings on the floor to help specify the spatial location of Vince. Most importantly, we used a 2AFC question in which the participants were told that Vince could see himself in one but not the other of a pair of photographs, and this was followed by a 4AFC task with the same photographs. Unsurprisingly, accuracy in the 2AFC task was higher than that in the 4AFC task. However, performance was far from perfect even in the $2 \mathrm{AFC}$ task. Furthermore, in the 4AFC task, many people changed their response and selected the new option of responding that Vince could see himself in both scenes. This demonstrates that forcing them to choose between two photographs in the 2AFC task prevented them from responding with what they mistakenly believed was the correct answer-namely, that Vince could see himself in the mirror in both cases.
In Experiment 5, we took a different approach. Here, participants marked which nails in a wall were visible to a person facing a mirror, so that the wall with nails was behind the person. The results confirmed the participants' general insensitivity to the location of Venus's viewpoint. The participants expected the mirror to reflect the space in front of the mirror, with this area of visibility depending more on the location of the mirror than on the location of Venus.

The belief that what is visible in a mirror depends on the location of the mirror but not on Venus's viewpoint is in agreement with what was found by Bertamini and Parks (2005). In that study, the question was about projection size on the mirror itself and not visibility, but it is interesting that people claimed (incorrectly) that projection size would remain constant as the viewpoint was moved but that it would change when the object was moved.

The Venus effect is surprising if one considers how familiar people are with mirrors. We interact with mirrors in everyday life and use them, for instance, to drive a car. Even children as young as four 4 years old can locate a toy on the basis of information they gather from mirrors (Field \& Hogg, 1992). The present results demonstrate that understanding what is visible in a mirror from a given viewpoint is not knowledge that comes from experience with mirrors (which is vast) and is different from using mirrors to perform specific tasks like finding a toy, driving a car, or shaving.

In conclusion, people often say that a person (Venus) can see herself in a mirror when the layout makes this impossible. This effect does not require the face of Venus to be visible in the mirror to the observer. The Venus effect is closely related to the belief that one can see oneself before arriving in front of a mirror (the early error; Bertamini, Latto, \& Spooner, 2003; Croucher et al., 2002), and, more generally, the difficulty in appreciating how what is visible to you depends on your viewpoint.

\section{AUTHOR NOTE}

Correspondence concerning this article should be addressed to M. Bertamini, School of Psychology, University of Liverpool, Eleanor Rathbone Building, Liverpool L69 7ZA, England (e-mail: m.bertamini@, liverpool.ac.uk).

\section{REFERENCES}

BAKer, C., \& Henry, T. L. (EDS.) (2001). The National Gallery complete illustrated catalogue. London: National Gallery.

Bertamini, M., Latto, R., \& Spooner, A. (2003). The Venus effect: People's understanding of mirror reflections in paintings. Perception, 32, 593-599. doi:10.1068/p3418

Bertamini, M., \& Parks, T. E. (2005). On what people know about images on mirrors. Cognition, 98, 85-104. doi:10.1016/j .cognition.2004.11.002

Bertamini, M., Spooner, A., \& Hecht, H. (2003). Naive optics: Predicting and perceiving reflections in mirrors. Journal of Experimental Psychology: Human Perception \& Performance, 29, 982-1002. doi:10.1037/0096-1523.29.5.982

Croucher, C. J., Bertamini, M., \& Hecht, H. (2002). Naive optics: Understanding the geometry of mirror reflections. Journal of Experimental Psychology: Human Perception \& Performance, 28, 546-562. doi:10.1037//0096-1523.28.3.546

FIELD, J., \& HogG, V. (1992). Young children's ability to find objects reflected in mirrors. Australian Journal of Psychology, 44, 9-11. doi:10.1080/00049539208260156 
Flavell, J. H., Flavell, E. R., Green, F. L., \& Wilcox, S. A. (1981). The development of three spatial perspective-taking rules. Child Development, 52, 356-358.

Freeman, G. H., \& Halton, J. H. (1951). Note on exact treatment of contingency, goodness of fit and other problems of significance. Biometrika, 38, 141-149.

Gombrich, E. H. (1960). Art and illusion. Oxford: Phaidon.

Jones, L., Bertamini, M., \& Spooner, A. (2010). The eyes have it: Naive beliefs about reflections. Manuscript submitted for publication.

LAWSON, R., \& BERTAMini, M. (2006). Errors in judging information about reflections in mirrors. Perception, 35, 1265-1288. doi:10.1068/ p5498

LaWson, R., Bertamini, M., \& LiU, D. (2007). Overestimation of the projected size of objects on the surface of mirrors and windows. Journal of Experimental Psychology: Human Perception \& Performance, 33, 1027-1044. doi:10.1037/0096-1523.33.5.1027

PiAget, J., \& INHELdER, B. (1967). In the child's conception of space: The coordination of perspectives. New York: Norton.

Poglayen-Neuwall, S. (1934). Titian's pictures of the toilet of Venus and their copies. Art Bulletin, 16 (4), 358-384.

Winer, G. A., Cottrell, J. E., Gregg, V. R., Fournier, J. S., \& BICA, L. A. (2002). Fundamentally misunderstanding visual per- ception. American Psychologist, 57, 417-424. doi:10.1037//0003 -066 X.57.6-7.417

\section{NOTES}

1. There are also interesting errors that are not specific to mirrors but are related to how vision works. For example, many children and adults believe in extramission-light traveling from the eye to the object for the object to be seen (Winer, Cottrell, Gregg, Fournier, \& Bica, 2002) — and starting from the famous three-mountains experiment by Piaget and Inhelder (1967), researchers have studied children's problems in perspective taking. However, by the age of 5 years, children seem able to appreciate that asymmetrical objects will look different to observers in different locations (Flavell, Flavell, Green, \& Wilcox, 1981).

2. We argue that the Venus effect is not the consequence of limited time or limited richness of the images. Consistent with this idea, there has been much time to perform detailed examinations of the famous paintings cited in the introduction, yet they are still routinely described as depicting Venus admiring herself in a mirror.

(Manuscript received August 3, 2009; revision accepted for publication June 1, 2010.) 